\title{
AMENDMENTS
}

\section{Publisher Correction: Robust abatement pathways to tolerable climate futures require immediate global action}

\author{
J. R. Lamontagne (D), P. M. Reed, G. Marangoni (iD, K. Keller (iD) and G. G. Garner (iD) \\ Correction to: Nature Climate Change https://doi.org/10.1038/s41558-019-0426-8, published online 11 March 2019
}

The previous 'Journal peer review information' for this Letter was incorrect. The correct statement is "Nature Climate Change thanks Jan Kwakkel, Francesca Pianosi and Matthias Weitzel for their contribution to the peer review of this work." This statement has now been amended.

Published online: 16 April 2019

https://doi.org/10.1038/s41558-019-0480-2

\section{Publisher Correction: Southern Hemisphere subtropical drying as a transient response to warming}

J. M. Kale Sniderman (D), Josephine R. Brown, Jon D. Woodhead (D), Andrew D. King (D), Nathan P. Gillett, Katarzyna B. Tokarska (D), Katja Lorbacher, John Hellstrom (D), Russell N. Drysdale and Malte Meinshausen (D)

Correction to: Nature Climate Change https://doi.org/10.1038/s41558-019-0397-9, published online 11 February 2019

The previous 'Journal peer review information' for this Letter was incorrect. The correct statement is "Nature Climate Change thanks Jie He, Hanh Nguyen, Caroline Ummenhofer and other anonymous reviewer(s) for their contribution to the peer review of this work." This statement has now been amended.

Published online: 17 April 2019

https://doi.org/10.1038/s41558-019-0479-8

\section{Publisher Correction: Drivers of peak and decline}

Kuishuang Feng

Correction to: Nature Climate Change https://doi.org/10.1038/s41558-019-0421-0, published online 25 February 2019.

In the version of this News \& Views originally published, the linked paper was not included in the reference list. The correct reference is Le Quéré, C. et al. Nat. Clim. Change 9, 213-217 (2019). This has now been added as reference 4 in all versions of the News \& Views. 